1182 age 32 wks. Who needed mechanical ventilation because of respiraby slight hyperventilation. Chest wall compliance was calculated by dividing tidal volume ( $\mathrm{VT}$ ) by the change in esophageal pressure (Pes) obtained at different peak inspiratory pressures. Changes in Pes reflect the amount of airway pressure transmitted to the pleural space. Means for VT and Pes measurements were $\begin{array}{lrrrrrrrrr}\text { Pes (cmH20) } & 0.5 & 1.0 & 1.5 & 2.0 & 2.5 & 3.0 & 3.5 & 4.0 & 5.0 \\ V T \mathrm{ml} / \mathrm{kg} & 3.5 & 6.7 & 10.0 & 13.3 & 16.9 & 19.9 & 22.8 & 25.8 & 31.0\end{array}$ The results indicate that there is a linear correlation between VI and Pes $(r=0.95)$ up to maximal inflation of the lung. The lope of the regression was $6.4 \mathrm{~m} / \mathrm{cmH} 20 \mathrm{xkg}$, which is the value f chest wall compliance. No linear correlation was found beween airway pressure and Pes because the pressure volume curve $f$ the lung is not linear but becomes progressively flatter at high volumes. Because chest wall compliance is four to six times higher than the normal lung compliance, no more than a sixth to a fourth of the airway pressure can be transmitted to the esophagus during positive pressure ventilation. Transmission will be even smaller when lung compliance is decreased as it ccurs in hyaline membrane disease or when the tidal volume eaches the flatter part of the pressure volume curve of the lung his poor transmission may protect the cardiovascular system from the effects of positive pressure.

1183

LUNG PRESSURE VOLUME CURVE IN PREMATURE INFANTS WITH PDA. Tile Gerhardt, Eduardo Bancalari, University of Florida. Miami, School of Medicine, Dept. of Pediatrics Miami,

The effects of a left to right shunt through a patent ductus arteriosus (PDA) on the mechanical properties of the lung were evaluated in 16 premature infants, mean $\mathrm{BW} 1130 \mathrm{~g}$, GA 30 weeks. All infants required mechanical ventilation and pressure volume $(P / V)$ curves were constructed using the difference between airway and esophageal pressure as transpulmonary pressure (PL) and the tidal volume measured simultaneously at different peak inspirator pressures. Resul.ts of lung compliance (CL) (ml/cmH20xkg) were ompared with those obtained in normal infants and prematures with hyaline membrane disease (HMD).

\begin{tabular}{lcccccccc} 
LL & $\mathrm{cmH} 20$ & 5 & 10 & 15 & 20 & 25 & 30 & 35 \\
\hline IMA & $(\mathrm{N}=16)$ & 0.76 & 0.71 & 0.71 & 0.68 & 0.68 & 0.65 & 0.61 \\
IMD & $(\mathrm{N}=16)$ & 0.48 & 0.50 & 0.54 & 0.51 & 0.46 & 0.41 & 0.36 \\
Tormal $(\mathrm{N}=2)$ & 2.24 & 2.12 & 1.73 & 1.55 & 1.34 & 1.20 & 1.04
\end{tabular}

nfants with PDA showed a low CL which only decreased slightly with increasing PL, reflecting an almost linear $\mathrm{P} / \mathrm{V}$ curve. This is in contrast to the PV curve obtained in normal infants and in infants with HMD in whom after an initial linear portion there is progressive flattening due to alveolar overdistension resulting $\mathrm{n}$ a decrease in CL. The decreased CL and the linear course of he $P / V$ curve in infants with PDA may be due to increased inters itial fluid leading to a decrease in tissue elasticity that revents alveolar overdistension. The characteristics of the $P / V$ curve in infants with PDA can be used to differentiate between

1184

\section{PULMONARY VASODILATOR ACTION OF TOLAZOLINE IN THE}

NEWBORN. Boyd $W$. Goetzman and Jay M. Milstein. University of California, Davis - Sacramento Medical

Center, Sacramento, California. (Spon. by Richard P. Wennberg.) Tolazol ine has been reported to reduce the elevated pulmonary vascular resistance found in some clinical conditions, including the syndrome of persistence of the fetal circulation in the newborn. Tolazoline, an $\alpha$-adrenergic blocking agent, also has direct actions on cardiac and smooth muscle which are described as "histamine-1ike." We evaluated the pulmonary vasodilator effect of tolazoline in newborn lambs before and after the administration of the specific histamine $\mathrm{H}_{1}$ - and $\mathrm{H}_{2}$-receptor antagonists, diphenhydramine and metiamide, respectively. Lambs, $0-3$ days old, were anesthetized and instrumented for measurement of pulmonary artery pressure, left atrial pressure and pulmonary blood flow. Pulmonary vascular resistance, PVR, was then calculated. Pharmacologic agents were administered in bolus form via the inferior vena cava in the following doses: tolazoline, $1 \mathrm{mg} / \mathrm{kg}$; diphenhydramine, $5 \mathrm{mg} / \mathrm{kg}$; and metiamide, $5 \mathrm{mg} / \mathrm{kg}$. The mean change in pulmonary vascular resistance, $: \triangle \mathrm{PVR}$, produced by tolazoline after histamine receptor blockade is given below.

\begin{tabular}{lccccc}
\hline $\mathrm{n}$ & 8 & 4 & 4 & 8 \\
Histamine Pntagonist & None & $\mathrm{H}_{1}$ & $\mathrm{H}_{2}$ & $\mathrm{H}_{1}+\mathrm{H}_{2}$ \\
\hline $\mathrm{g} \Delta \mathrm{PVR}$ & $-25 \pm 8$ & $-13 \pm 4$ & $-18 \pm 6$ & $+6 \pm 8$ \\
\hline
\end{tabular}

It is concluded that the pulmonary vasodilator action of tolazoline is entirely mediated by histamine $\mathrm{H}_{1}^{-}$and $\mathrm{H}_{2}$ tolazoline
receptors.

1185 INCREASED WORK OF BREATHING ASSOCIATED WITH NASAL PRONG CPAP. Steven L. Goldman, June P. Brady, and Fe M. Dumpit Uriv. of Calif., Childrens Hospital, Dept. f Ped., and Cardiovaculory failure Nasal prong CPAP maline membrane disease(HMD) by increasing work of breathing. In 6 preterm infants with HMD, respiratory work of breathing. In 6 preterm infants $(\dot{v})$, tidal volume $\left(v_{T}\right)$, esophageal pressure ( $\triangle$ Pes), and arterial blood gases were compared using nasal prongs and Bourns face mask at the same FiO2 and CPAP. $f \quad \frac{\text { Mask }}{83} \frac{\text { Prongs }}{74} \frac{p}{.04}$ There was no difference in $\dot{V}, p H$, $\mathrm{VT}_{\mathrm{T}}(\mathrm{ml} / \mathrm{kg}) \quad 4.3 \quad 5.0 \quad$ NS cantly higher, and $\mathrm{V}_{\mathrm{m}}$ and $\Delta P e s$ $\dot{\mathrm{V}}(\mathrm{ml} / \mathrm{kg} / \mathrm{min}) 358 \quad 370 \quad$ NS tended to decrease with mask $\begin{array}{lllll}\text { P02 } & 87 & 77 & .05 & \text { CPAP. Compliance was lower with }\end{array}$ $\triangle \operatorname{Pes}\left(\mathrm{cm} \mathrm{H} \mathrm{H}_{2} \mathrm{O}\right) 10.4 \quad 12.5 \quad .08$ the mask but the change was not significant $(\mathrm{N}=3)$. The total $\triangle$ Pes over I minute decreased with the mask. Because there was no increase in compliance with the mask, this decrease in $\triangle$ Pes represents a decrease in resistive work. This was confirmed in 3 infants whose work of breathing was $26 \%$ less with the mask compared to the prongs. The resistance of the prongs is 10 times the resistance of the mask. With a constant $\dot{V}, f$ must decrease and $V_{T}$ must increase if the obligate increase in work is to be minimized.

Our data suggest that the high resistance inherent in nasal prongs must increase work of breathing. Thus, otner modes of delivery of CPAP should be considered in the already compromised infant wi.th HMD.

\section{6} in 90 infants $(800-5140 \mathrm{~g})$ who were intubated 13,371 hours $(1.5$ patient years). There were 118 tubes in place an average of 147 hours $(38-668)$. 95 tubes were clear at extubation, 18 thinly coated with mucus but clear, and 5 occluded. 3/5 occluded tubes had a Murphy eye. $3 / 5$ were partially occluded and only discovered at extubation. All occluded tubes were from infants weighing $>2100 \mathrm{~g}$. Bronchial intubation (BI) occured 36 times in 29 patients, 20 immediately after intubation. $50 \%$ of BI were in patients $<1500 \mathrm{~g}$. 578 of late BI occurred with inadequate taping. Accidental extubation occurred 6 times in 5 infants weighing 1220 $+480 \mathrm{~g}$. Their activity was normal; 2 had inadequate taping. Endotracheal tubes were changed 21 times in 13 infants after 1.5461 hours of intubation; 2 for occlusion, 4 for suspected occl sion, 6 for no air leak at $15 \mathrm{~cm} \mathrm{H2O}, 3$ for malposition and 6 miscellaneous. On 88 occasions the tube was resutured and taped, 22 due to initial malposition of the tube. Of the remaining 66 , 178 were high, 338 low and 508 loose. Retaping and suturing occurred every 8.4 days on average. Slight bleeding occurred with suctioning in 30 patients 78 of the time. No infant had pulmonary hemorrhage. There was no evidence of subglottic stenosis at post or discharge despite 38-1102 hours of intubation. We conclude that 1) tube occlusion usually occurs in large babies, 2) malposition and accidental extubation usually occurs in small babies, 3) the tube complication rate is low, 4) th the complications are preventable.

\section{7} PULMONARY FUNCTION ABNORMALITIES IN ASYMPTOMATIC CHILDREN FOLLOWING HYDROCARBON PNEUMONITIS. Denn is Gurwitz, M. Kattan, H. Levison and J.A.G. Culham Department of Pediatrics To assess the effect of hydrocarbon pneumonitis on the developing lung we studied the pulmonary function of seventeen asymptomatic subjects, eight to fourteen years after the initial insult. Fourteen of the 17 subjects $(82 \%)$ had one or more pulmonary function abnormalities, the most frequent being a high volume of isoflow. Volume of is of low, the ratio of residual volume to total lung capacity, slope of Phase 111 , flow rates at 50 and $25 \%$ of vital capacity and $60 \%$ of the total lung capacity, one second forced expiratory volume and maximum mid expiratory flow rate differed significantly $(p<.05)$ from age and height matched controls. Closing volume and closing capacity were not significantly different. The data show that residual abnormalities are present following hydrocarbon pneumonitis. This could be explained on the basis of small airway obstruction and/or loss of elastic recoil and are similar to the earliest changes seen in smokers and adult patients with chronic obstructive lung disease. These children may be at higher risk for the development of chronic lung disease in adulthood when exposed to exogenous factors such as air pollution or smoking. 